\title{
GENERAL NUTRITIONAL PRACTICES IN SCHOOL-AGE CHILDREN OF KHARKIV REGION
}

\author{
Chaychenko T., Gonchar M., Chumachenko T., Klymenko V., \\ Rybka O., Kharkova M., Petrenko E., Starik D.
}

\section{Kharkiv National Medical University}

\begin{abstract}
Pediatric nutrition has become one of the cornerstones of global health due to its association with the most insidious non-communicable diseases. As part of the research "Assessment of the current nutritional status, nutrition-related health problems in school-age children in Ukraine", conducted at Kharkiv National Medical University, general nutritional habits and practices of school-age children of Kharkiv region were assessed for the further elaboration of educational programs. Current nutritional status was assessed by using original questionnaire (adapted from the FAO recommendations) in 392 school-age children, divided into 3 groups: primary school (75 children aged 6-9), middle school (202 children aged 10-14) and high school (115 children aged 15-18.), who were randomly selected in urban and rural areas of the region.

The study showed a trend for irregular nutrition, ascending with age. Family traditions for regular meals are still powerful. There is a decrease of this tendency in high-school age, when the quarter of children become less sure in exact impact factors on the choice of food. It was established that about $20 \%$ of school-age children skipped their breakfasts, but understood possible health-related outcomes. Almost all children were found to have unhealthy snacks such as pastry, sweets and sugary beverages. Besides, $80 \%$ of school-age children spend their pocket money on food and purchase it at the nearest groceries or school canteen. And this tendency is statistically higher in middle-school age. There is no particular involvement of parents in day-time nourishment as just $13 \%$ of them give lunch-boxes to their children. Conclusions:

1. Nutrition of school-age children is not balanced with incorrect energy distribution during the working day: tendency for skipping breakfasts and to have multiple unhealthy snacks between main meals (pastry, sweets, sugary drinks etc.).

2. Educational programs for school-aged children must be focused on the choice of healthy snacks and drinks as well as outcomes of inappropriate nutrition. Particular attention should be paid to the education of middle-school children.

3. Parents should be actively involved in the educational programs due to the significant influence of family traditions on the nutrition of school-age children.
\end{abstract}

Key words: Nutrition, general nutritional practices, school-age children, educational programs.

Introduction. Nutrition of children has become one of the most important problems of the international health policy. The WHO is a global leader, which has recently proclaimed: "In September 2017, we jointly launched The State of Food Security and Nutrition in the World, marking the beginning of a new era in monitoring progress towards achieving a world without hunger and malnutrition, within the framework

Corresponding Author:

Tetyana Chaychenko, MD, PhD, Professor

of Department of Pediatrics 1 and Neonatology

of Kharkiv National Medical University, Ukraine.

E-mail: tatyana.chaychenko@gmail.com of the Sustainable Development Goals" [1]. Beside the malnutrition breast feeding [2] and pediatric obesity are in the focus [3]. Moreover, overweight was stated as the one of the forms of malnutrition, which underlines the double burden of disease in low and low-middle income countries [4] due to endorsement of economic costs of the problem [5]. According to the global recommendations, the specific national data about state of nutrition are necessary to attain the goal.

\section{Purposes, subjects and methods:}

2.1. Purpose - was to assess general nutritional habits and practices of school-age children of Kharkiv region for further development of nutrition education programme. 
2.2. Subjects \& Methods. This work is a part of research "Assessment of the current nutritional status, nutrition-related health problems in school-age children in Ukraine", conducted at Kharkiv National Medical University for the development and further implementation of social education program for prevention of noncommunicable diseases.

A cross-sectional study was conducted in three different geographic regions of Ukraine. The present data provides survey results of Kharkiv region children (as a representative of eastern part of country).

For the survey the original questionnaire (adapted according to the FAO recommendations) was elaborated for the analysis of broader context (economic, social, environmental factors) that influences on nutrition.

Assessment of current nutritional status in school-age children of 3 age groups (aged 6-9, $10-14,15-18)$, who were randomly selected in urban and rural areas of region, was performed.

The total number of participants was 392 schoolage children. The high school group (aged 15-17) consisted of 115 children aged $15.28 \pm 1.47$ that included 29(25.22\%) boys and 86 (74.78\%) girls.

The middle school group (aged 10-14) consisted of 202 children aged $12.55 \pm 1.40$ that included 95 (47.03 \%) boys and 102 (52.97 \%) girls.

The primary school group (aged 6-9) consisted of 75 children aged $8.20+1.27$ that included 43 (57.33 \%) boys and 32 (42.67\%) girls.

The study was approved by the institutional Committee in Ethics and Bioethics of Kharkiv National Medical University. Written consent from parents and children was obtained for every participant.

Standard statistics was used for the data analysis.

Conflict of interests. There is no conflict of interests.

3. Results and discussion. The survey results have shown that $83.16 \%$ school age children have regular breakfast and vast majority of them (84.84 \%) do it at home and $15.01 \%$ at school.

Regular lunch is eaten by $93.31 \%$ of children, $45.97 \%$ of them have their lunch at home after school, $44.93 \%$ at school and $9.83 \%$ in other places. The study showed that the number of primary and middle-school children had their lunch more regularly ( $~(=0.03)$ than high school children.

Moreover, $13.26 \%$ respondents (with no difference in groups) take the meal precooked by their parents, 31.67\% have their lunch in school canteen and $9.83 \%$ purchase meal in different cafeteria with the pocket money. And the tendency for purchasing meal is age-dependent (from $5.5 \%$ primary school to $18.64 \%$ high school, $\mathrm{p}=0.03$ )

Dinner is usually eaten at home (93.18\%). But it is less regular $(ð<0.01)$ for high-school (88.7 $\%)$ as compared to middle-school (97.02) and primary-school (95.9\%) children.

Snacks between main meals are eaten by $76.53 \%$ children. The list of the most common snacks is as follows:

- $82.88 \%$ - pastry, which is less typical for primary-school (18.9\%) and the most common for middle-school (72.55 \%) with a further decrease in high-school (54.12 \%);

- $58.33 \%$ - seasonal fruit (the tendency is the same);

- $50.33 \%$ - sandwiches with cheese or sausages (the tendency is the same);

" $51.66 \%$ - sweets, less common $(\mathrm{p}<0.001)$ for primary-school children (12.6\%) with no difference between middle- and high-school;

- $16.33 \%$ - potato chips and crisps, more popular $(\mathrm{p}=0.02)$ between middle-school children $(2.57 \%)$

The most favored drinks include tea (46.66\%), sweet sparkling beverages (mainly for middle age $-23.66 \%$ ), juice (32.33\%), coffee (mainly in girls from middle and high school - $16.99 \%$ ), energy drinks (3.66 \%).

About $70 \%$ of respondents spend their pocket money on meals and additionally to this $13 \%$ do it when they have money.

The vast majority of children purchase their snacks in school canteen (53.41\%) and the nearest groceries (63.66 \%). Meanwhile, $4.96 \%$ buy street food. Only $37.26 \%$ of children buy appropriate lunch and it is mainly ( $ð<0.01)$ middleage children (66.18\%).

The family influence (59.94\%) is the most significant factor for choosing meals that children normally consume. This factor is more powerful in primary middle school (more than $60 \%$ ) and significantly $(\mathrm{p}<0.01)$ drops down in high-school (48.69\%). Impact of mass-media advertisement $(10.2 \%)$ and peers $(9.43 \%)$ is relatively low. Alternatively, $21.93 \%$ of respondents were unable to explain what exactly influences their food priorities. Interestingly, $25 \%$ of high-school children are beside them.

Main meal together with two snacks is considered to be a good nutritional plan, which is easy to follow (for 75.51\%). 
Surprisingly, only $45.15 \%$ of children reported that assorted nutrition was a good thing, 33.43\% were against this statement and $21.41 \%$ were not sure. According to the responses, an assorted nutrition is available for $76.53 \%$.

Taking into account the fact that breakfast is a main meal that serves to the appropriate energy distribution during the day, we paid a particular attention to this meal in the frames of survey. Thus, $90.83 \%$ of children consider breakfast to be an essential meal. But they become less sure in this in the middle-age ( $<<0.01$ with primary and high school). It is not difficult to have regular breakfast for $64.41 \%$ children and occasional difficulties are met by $26.53 \%$.

Assessment of "open questions" concerning health-related problems due to skipped breakfast has shown that they are aware of potential harm. Along these lines, $42.82 \%$ of children are concerned about gastrointestinal disorders (abdominal pain, gastritis, ulcer, vomiting). The number of middle-school children is significantly $(ð<0.01)$ higher beside them $(57.42 \%)$ as compared to the primary-school (29.33\%) and high-school (34.78\%).

Potential general problems (headaches, tiredness, fatigue, moodiness, low energy), directly related to school performance were reported by $53.01 \%$ of participants. Markedly general problems were more frequently $(\mathrm{p}<0.0001)$ reported by high-school (59.13 \%) and middleschool (57.92 \%) children versus primary-school ones (30.66\%). Relation to the overweight, underweight or diabetes was marked just by $1 \%$ of responders.

Summarizing the obtained data, $20 \%$ of school-age children have no breakfast, but they are mainly aware of health-related outcome.
The tendency to irregular nutrition decreases with age, but it is not dramatic due to powerful influence of family traditions, which decreases in high school age, when the quarter of children become less sure in exact impact factors on the choice of food.

Nutritional pattern of school-age children during the working day attracts particular attention. On the one hand almost half children have their lunch after school at home and one third of them in school canteen. On the other hand, there is no particular involvement of parents in day-time nourishment as only13 \% of them give lunch-boxes to their children.

The study showed that almost all children had unhealthy snacks such as pastry, sweets and sugary beverages. And this tendency is statistically higher in middle-school age. Eighty percent of school-age children spend their pocket money on food and purchase it at the nearest groceries or school canteen.

\section{Conclusions:}

1. Nutrition of school-age children is not balanced with incorrect energy distribution during the working day: tendency for skipping breakfasts and to have multiple unhealthy snacks between main meals (pastry, sweets, sugary drinks etc.).

2. Educational programs for school-aged children must be focused on the choice of healthy snacks and drinks as well as outcomes of inappropriate nutrition. Particular attention should be paid to the education of school-children to prevent nutrition-related problems in middleschool.

3. Parents should be actively involved into the educational programs due to the significant influence of family traditions on the nutrition of school-age children.

\section{References:}

1. FAO, IFAD, UNICEF, WFP and WHO. 2018. The State of Food Security and Nutrition in the World 2018. Building climate resilience for food security and nutrition. Rome, FAO.

2. UNICEF, WHO. Capture the Moment - Early initiation of breastfeeding: The best start for every newborn. New York: UNICEF; 2018.

3. Commission on Ending Childhood Obesity (2016). Report of the Commission on Ending Childhood Obesity.

4. WHO Fact sheet $N^{\circ} 311$. Updated January 2015.

5. World Obesity Federation (2017) Global data on costs of the consequences of obesity]. This tremendous problem forced United Nations to announce a decade of nutrition from 2016 till 2025 [United Nations (2018) Decade of Nutrition 2016-2025.

Received: 07-Jul. - 2018

Accepted: 13-Sep. - 2018 